\section{Diagnóstico e Tratamento do Criptorquismo}

\section{RESUMO}

O criptorquismo corresponde à localização extra-escrotal do testículo, atingindo cerca de $3 \%$ dos recém-nascidos e 0,5 a $1,0 \%$ dos adultos. Geralmente é um achado clínico isolado, porém em $10 \%$ dos casos pode estar associado a disfunções hipotalâmico-hipofisárias, doenças genéticas ou embrionárias, e sua associação com outras anormalidades genitais, como a hipospádia e o micropênis, aumenta a probabilidade de se tratar de um estado intersexual. A exata descrição da localização testicular em repouso e sua mobilidade durante o exame físico são essenciais para o adequado diagnóstico, tratamento e prognóstico evolutivo. O diagnóstico é clínico, exigindo cuidadoso exame físico. O diagnóstico complementar por exames de imagem tem valor limitado. A avaliação gonadotrófica e da secreção hormonal testicular pode ser informativa nos primeiros 6 meses de vida ou na época puberal, períodos em que o eixo hipotálamo-hipofisário encontra-se ativado. O tratamento clínico é indicado em pacientes com testículo retido ou com grande retratilidade, utilizando-se a gonadotrofina coriônica humana na dose de 50Ul/kg/semana durante 6 semanas. O tratamento clínico está contra-indicado na presença de hérnia inguino-escrotal comprovada, varicocele ou cisto de cordão espermático. A cirurgia é indicada na falha terapêutica clínica ou nos testículos ectópicos. A precocidade terapêutica (1-2 anos vida) tem sido apontada como um aspecto decisivo na prevenção das principais complicaçōes do criptorquismo, como a esterilidade e o maior risco neoplásico gonadal. (Arq Bras Endocrinol Metab 2005;49/1:165-171)

Descritores: Criptorquismo; Gonadotrofina coriônica humana; Testículo; Tratamento

\begin{abstract}
Cryptorchidism: Diagnosis And Treatment.

Cryptorchidism corresponds to the extra-scrotal position of the testis, and can be found in $3 \%$ of the term newborns and 0.5 to $1.0 \%$ of adults. It is usually an isolated clinical feature, but in around $10 \%$ of the cases can be associated to hypothalamic-pituitary dysfunction and genetic or embryonic disorders. The presence of additional genital abnormalities, such as hypospadia or micropenis, increases the probability of the diagnosis of an intersex condition. Detailed description of the testicular anatomic position is essential to adequate diagnosis, treatment and prognostic evaluation. The diagnosis of cryptorchidism is made by clinical examination. The complementary exams, such as image analysis, add limited information on the diagnosis. Gonadotropins and testicular hormones measurement can be useful if the hypothalamic-pituitary-gonadal axis is activated, as observed during the first 6 months of life or during puberty. Clinical treatment is indicated in patients with retained testis or in severely retractile testis. In these cases, human chorionic gonadotropin is employed at a dose of $50 \mathrm{lU} / \mathrm{kg} /$ week for 6 conseculive weeks. Clinical treatment cannot be used in cases of confirmed inguinal hernia, varicocele or spermatic cord cysts. Surgical correction is indicated after failure of clinical treatment or for ectopic testes. The long-term prognosis of cryptorchidism seems to be related to the precocity of the therapy. Therefore, recognition and treatment of cryptorchid testes should be done during the first 2 years of life, potentially improving the risks of infertility and gonadal neoplasia. (Arq Bras Endocrinol Metab 2005;49/1:165-171)
\end{abstract}

Keywords: Cryptorchidism; Human chorionic gonadotropin; Testis; Treatment

\section{Carlos Alberto Longui}

Unidade de Endocrinologia Pediátrica, Departamento de Pediatria da Faculdade de Ciências Médicas da Santa Casa de São Paulo, SP.
Recebido em 03/10/04

Aceito em 15/11/04 
C RIPTORQUISMO É A DENOMINAÇÃO genérica que descreve a localização extra-escrotal do testículo, representando a mais freqüente anormalidade genital masculina. A migração testicular ocorre em fases que se completam no final da gestação. Portanto, a incidência do criptorquismo em recém-nascidos está relacionada à duração da gestação (tabela 1 ).

Embora o criptorquismo seja habitualmente um achado isolado, em 10-20\% dos casos pode estar associado a disfunções hipotalâmico-hipofisárias, doenças genéticas ou embrionárias ou malformações congênitas da parede abdominal, sendo que a associação do criptorquismo com outras anormalidades genitais, como a hipospádia e o micropênis, aumenta a probabilidade de se tratar de um estado intersexual.

As complicações decorrentes do criptorquismo estão principalmente relacionadas ao grau de anormalidade da localização testicular. Podem ser agudas, como a torção ou maior propensão ao trauma, ou crônicas, como a esterilidade, maior risco neoplásico e insuficiente produção androgênica. Podem ainda ser observadas repercussões psicológicas secundárias ao escroto vazio, à possível esterilidade e às dúvidas dos familiares e pacientes quanto à influência da doença sobre o desempenho sexual.

\section{Classificação e Descrição Topográfica dos Testículos}

Existe grande discrepância entre as classificações empregadas por diversos autores, bem como falta de detalhes quanto à localização testicular antes e depois do tratamento, influindo significantemente nas diferentes incidências relatadas, bem como na descrição do sucesso terapêutico com diferentes fármacos. Portanto, uma descrição minuciosa da localização testicular e uma classificação detalhada devem ser empregadas para que o prognóstico evolutivo e os resultados terapêuticos possam ser comparados entre os diferentes Serviços.

Tabela 1. Incidência do criptorquismo.

\begin{tabular}{cccc}
\hline Idade & Peso $(\mathbf{g})$ & Incidência (\%) \\
\hline RN Prematuros & $451-910$ & 100,0 \\
& $911-1810$ & 62,0 \\
& $1811-2040$ & & 25,0 \\
& $2041-2490$ & \multirow{2}{*}{ Total } & 30,3 \\
& & 12,0 \\
RN Termo & $2491-2720$ & & 3,3 \\
& $2721-3630$ & & 0,7 \\
& $3631-5210$ & \multirow{2}{*}{ Total } & 3,4 \\
1 ano & & & $0,7-1,0$ \\
Escolar & & & $0,76-0,95$ \\
Adultos & & & $0,7-1,0$ \\
\hline
\end{tabular}

De forma simplificada, a tabela 2 resume a classificação do criptorquismo que empregamos na Unidade de Endocrinologia Pediátrica do Departamento de Pediatria da Santa Casa de São Paulo. Cada testículo é classificado quanto a ser palpável ou não e quanto a estar ou não no trajeto normal de migração. A caracterização topográfica do testículo deve ser realizada como descrito na figura 1 .

A descrição completa deve identificar a localização testicular antes e depois do tratamento, bem como a localização do testículo em repouso e durante a manobra de tração. Isto permite a um mesmo observador realizar o acompanhamento evolutivo de cada caso. Esta descrição tem sido empregada de maneira prática e reprodutível em nossa Unidade, sendo uma forma eficaz de caracterizar a localização testicular ao exame físico.

O exemplo que se segue resume uma situação hipotética: na primeira consulta detecta-se um testículo que em repouso encontra-se na região canalicular (B) e que sob tração pode ser deslocado até a base peniana (D) sem, contudo, entrar no escroto. Após tratamento hormonal, localiza-se em repouso na região pré-escrotal $(\mathrm{C})$ e sob tração pode ser trazido ao terço médio do escroto $(\mathrm{F})$. A descrição completa desta situação pode ser resumida por: $\mathrm{B} / \mathrm{D} \rightarrow \mathrm{C} / \mathrm{F}$, representando uma resposta parcial de um testículo inicialmente retido canalicular e que após o tratamento torna-se retrátil, e, portanto, passível de um segundo ciclo de tratamento hormonal.

\section{Exame Físico}

O criptorquismo é uma anormalidade de diagnóstico exclusivamente clínico, durante o exame físico dos genitais. Assim como ocorre nos estados intersexuais, a falta de exame clínico rotineiro dos genitais tem sido uma das causas mais freqüentes de atraso no diagnóstico.

Tabela 2. Classificação do criptorquismo.

Testículo Palpável
Trajeto Normal
Retrátil
Retido (intracanalicular, pré-escrotal)
Trajeto Anormal (ectópico)
Inguinal superficial
Pubopeniano
Perineal
Femural
Cruzado (transverso)
Testículo Não-palpável
Intra-abdominal (criptorquismo verdadeiro)
Anorquismo




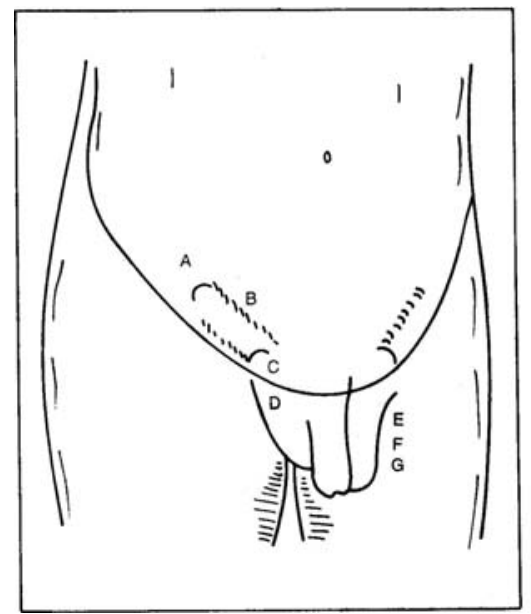

A: Intra-abdominal, próximo ao ane

inguinal interno.

B: Intracanalicular, entre $o$ ane

inguinal interno e o externo.

C: Regiăo pré-escrotal, entre o anel

inguinal externo e a base peniana.

D: Regiăo pré-escrotal,

correspondente à base peniana

E: Região intra-escrotal, terço

superior.

F: Região intra-escrotal, terço médio.

G: Região intra-escrotal, terço inferior.

Figura 1. Descrição topográfica dos testículos retidos

O reconhecimento da correta localização testicular depende de um exame cuidadoso, com o paciente calmo e se necessário utilizando-se manobras de inibição do reflexo cremastérico, como a posição de cócoras ou semi-sentada com joelhos fletidos, mãos do examinador e ambiente aquecidos. A palpação deve ser suave, utilizando-se sabão ou talco para que a mão deslize sobre o ligamento inguinal, desde a espinha ilíaca ântero-superior até a entrada do escroto. Esta manobra consegue evidenciar um "ressalto" testicular, permitindo a localização gonadal. A seguir, com a mão esquerda comprimindo o funículo espermático de cima para baixo (inibindo o reflexo cremastérico) e com a direita tracionando o testículo distalmente, determina-se a localização testicular sob tração, que representa o ponto mais distal que o funículo espermático permite à descida testicular.

A obesidade representa um fator que dificulta a detecção testicular e o reconhecimento da presença de hérnia inguinal associada. O preenchimento da parte superior do escroto pelo tecido adiposo confere ao mesmo um aspecto hipoplásico que deve ser diferenciado da hipoplasia resultante da ausência do testículo na região intraescrotal.

A persistência peritônio-vaginal isolada é um achado comum em pacientes criptorquídicos, porém sem nenhum significado patológico adicional. Deve ser diferenciada da hérnia inguinal antes da indicação do tratamento hormonal, pois o uso de hCG em portadores de hérnia patente pode aumentar o volume dos componentes do funículo espermático e facilitar a compressão e isquemia testicular. Nos pacientes com hérnia inguinal existe uma insuficiência do anel inguinal interno, permitindo a herniação de estruturas abdominais, especialmente alças intestinais, através do canal inguinal.

À inspeção é possível observar hipoplasia escrotal, assimétrica ou simétrica, sugerindo uma predominante posição extra-escrotal dos testículos. A pesquisa do reflexo cremastérico, pelo estímulo da face interna da coxa, demonstra o grau de retratilidade testicular, e quando acompanhado de retração do escroto evidencia a inserção do gubernáculo no fundo do escroto. Este é um valioso sinal clínico de bom prognóstico de resposta ao tratamento hormonal.

\section{Testículos Retráteis}

Este é outro aspecto controverso, sendo que para alguns autores, o testículo retrátil é aquele que está posicionado dentro do escroto e que esporadicamente (relacionado ao reflexo cremastérico) deixa o escroto apenas transitoriamente, não necessitando, portanto, qualquer medida terapêutica.

Porém, o grau de retratilidade testicular é muito variável. Nos casos leves, como acima descrito, a melhor conduta é apenas a observação clínica. A retratilidade de maior severidade induz a uma localização testicular predominantemente extra-escrotal, gerando conseqüências semelhantes às descritas para os testículos criptorquídicos. Nestes casos, os testículos poder ser trazidos ao escroto durante a tração exercida no exame físico, mas imediatamente saem do escroto após cessada a manobra de tração. Nestes casos, observa-se freqüentemente a associação de hipoplasia escrotal ou a redução do volume testicular. Em conjunto, estes 
achados determinam que o tratamento deva ser iniciado, à semelhança do que se faz com os outros tipos de criptorquismo.

\section{Criptorquismo Como um Sinal de Intersexo}

Em algumas anormalidades da diferenciação sexual, o testículo criptorquídico pode ser a única manifestação genital durante a infância. Isto ocorre na síndrome de Klinefelter e na síndrome de Noonan. Por outro lado, a associação de duas ou mais anormalidades genitais aumenta a probabilidade de que o criptorquismo seja uma das manifestações de um estado intersexual. Situações como testículos não-palpáveis bilateralmente (com ou sem virilização precoce associada), criptorquismo uni ou bilateral associado à hipospadia e/ou micropênis devem levantar a questão da intersexualidade.

Até $20 \%$ dos pacientes criptorquídicos podem apresentar um testículo não-palpável, e em $4 \%$ dos casos o testículo está realmente ausente (anorquismo bilateral, ou monorquismo quando a ausência é unilateral). Alguns testículos não-palpáveis encontram-se na região intra-abdominal e apresentam graus variáveis de disgenesia. Um número menor de gônadas nãopalpáveis intra-abdominais é representado por gônada mista ou ovotestis (testículo e ovário juntos na mesma gônada) e mesmo ovário "normal" em meninas portadoras de hiperplasia adrenal congênita com virilização completa do genital externo, o que induziu a uma determinação errônea do sexo social como sendo masculino. Nesta última eventualidade, pode haver uma crise de perda de sal nas primeiras semanas de vida ou uma virilização progressiva desde os primeiros meses de vida.

A presença de hipospadia associada ao criptorquismo também é freqüientemente observada nos casos de pseudo-hermafroditismo masculino. A gônada criptorquídica é habitualmente disgenética e com insuficiente produção androgênica. Ocorre também redução da produção do hormônio inibidor dos dutos de Müller, o que determina a presença de resquícios müllerianos como o útero, trompas e porção proximal da vagina. Um exemplo típico desta eventualidade é a disgenesia gonadal mista associada ao cariótipo $45, \mathrm{X} / 46, \mathrm{XY}$

\section{Diagnóstico Complementar}

Como já referido, o diagnóstico do criptorquismo é feito pelo exame do genital externo. Quando um exame físico adequado não consegue reconhecer a localização gonadal, esta pode ser intra-abdominal ou mesmo não existir.
Os diversos métodos utilizados para a localização de um testículo não-palpável possuem baixa sensibilidade. A ultrassonografia realizada com transdutor de $5-7 \mathrm{MHz}$ tem um custo/benefício melhor e habitualmente permite a detecção de testículos localizados junto ao anel inguinal interno. Alem disso, a US é útil na identificação de resquícios müllerianos e pode reconhecer o deferente, porém com baixa sensibilidade para alterações anatômicas dos mesmos. A tomografia computadorizada apresenta grande número de resultados falso-negativos (cerca de 44\%), além de empregar radiação ionizante e necessitar de sedação. A ressonância magnética nuclear é pouco superior à tomografia, porém ainda com baixa sensibilidade. A necessidade de sedação também é um fator limitante para a RM. A laparoscopia diagnóstica e terapêutica tem sido utilizada no criptorquismo verdadeiro, mas ainda encontrase em fase experimental em centros de excelência. Permitem uma identificação precisa da localização testicular, das características do funículo espermático e do epidídimo. É um dos métodos seguros para a confirmação do anorquismo unilateral. Depende diretamente da experiência do cirurgião e da disponibilidade de material especializado para sua realização em crianças pequenas.

Em casos específicos de testículos não-palpáveis bilateralmente, o teste de estímulo agudo com gonadotrofina coriônica humana (hCG) é de grande valia no reconhecimento do anorquismo bilateral. Emprega-se a dose de $100 \mathrm{UI} / \mathrm{Kg} /$ dia (máximo de 2000UI/dia), por via IM, durante 5 dias consecutivos. Realiza-se a determinação da concentração sérica de testosterona antes e 24 h após a $5^{\text {a }}$ dose do hCG. A concentração sérica de $\beta$-hCG também é determinada na amostra obtida após tratamento para a confirmação de que o estímulo tenha sido adequado $(\beta-\mathrm{hCG}>$ $20 \mathrm{mU} / \mathrm{mL}$ ). Um incremento da testosterona superior a 30ng/dL é sugestivo da presença de tecido testicular funcionante em pelo menos um dos lados, exigindo a exploração cirúrgica ou laparoscópica bilateral.

\section{Tratamento}

O tratamento do criptorquismo tem como objetivo o posicionamento intra-escrotal do testículo com o intuito de minimizar o trauma, reduzir o risco de torção, facilitar a palpação gonadal, garantindo uma melhor observação clínica ao longo prazo, bem como tentar minimizar os riscos de insuficiência testicular e de desenvolvimento neoplásico.

Idade ideal: Apesar de todos os esforços para se determinar o melhor momento para a correção do criptorquismo, ainda não existem evidências consistentes de que o tratamento precoce seja capaz de pre- 
venir as mais importantes alterações associadas a ele. Por outro lado, vários aspectos devem ser considerados na escolha da idade de indicação do tratamento. Alguns sinais histopatológicos já estão presentes na vida intrauterina e se agravam durante o primeiro ano, tornando-se evidentes e característicos já no segundo ano de vida. O tratamento precoce, clínico-hormonal ou cirúrgico, realizado por urologista ou cirurgião pediátrico, não acrescenta nenhum fator de risco adicional. Existem algumas evidências iniciais de que a correção mais precoce possa reduzir o risco de neoplasias nos testículos criptorquídicos. A migração testicular pós-natal espontânea ocorre geralmente nos primeiros 3 meses de vida e raramente após os 6-9 meses. Portanto, o presente estágio do conhecimento na área sugere que a época ideal para o tratamento hormonal seja entre os 9 e 12 meses, e em sua falha torna-se necessária a correção cirúrgica, que deve ser realizada próximo aos 12 meses de idade.

Tipo de criptorquismo: o modo de tratamento também depende do tipo de criptorquismo. Os testículos retidos, que representam a maior parte dos testículos criptorquídicos, devem ser tratados primariamente com hCG, desde que não haja associação com hérnia inguinal, cisto de cordão, hidrocele ou varicocele. Também serão tratados com hCG os testículos retráteis com alto grau de retratilidade ou com sinais de redução de volume testicular e hipoplasia escrotal. Testículos retidos que não respondam ao tratamento hormonal, bem como todos os testículos ectópicos e os testículos não-palpáveis terão sempre indicação cirúrgica para sua correção.

Tratamento hormonal: o tratamento com hCG foi introduzido na década de 30 , sendo empregado em doses cada vez menores. A dose atualmente indicada é de $50 \mathrm{UI} / \mathrm{Kg} /$ dia, via IM, uma vez por semana, com duração total de 6 semanas. É eficaz em 70 a $80 \%$ dos pacientes com testículos retráteis. Nos pacientes com testículos retidos, a eficácia do tratamento varia de 10 a $25 \%$ de acordo com a faixa etária. O hCG utilizado é um hormônio proteíco, produzido pela placenta, com grande homologia com a molécula do LH hipofisário. É classicamente extraído da urina de mulheres grávidas e age estimulando as células de Leydig do interstício testicular a produzir testosterona. É apresentada comercialmente sob a forma liofilizada, devendo ser diluído em solução fisiológica para a aplicação IM. Após reconstituição, a solução permanece estável por 4 semanas desde que mantida a $4^{\circ} \mathrm{C}$ e em condições estéreis. Apresenta meia vida plasmática de aproximadamente 3 dias e ação biológica de 5 a 7 dias. O uso de gonadotrofinas ainda é o tratamento hor- monal de escolha, especialmente em nosso meio. Recentemente, houve grande redução na disponibilidade das gonadotrofinas, e apenas algumas apresentações e concentrações estão ainda presentes no mercado nacional (tabela 3 ).

A associação do hCG com gonadotrofina humana da menopausa (hMG) não melhora a eficácia terapêutica, embora seja útil como teste de estímulo para avaliação funcional das células intersticiais de Leydig (geração de testosterona) e das células tubulares de Sertoli (geração de inibina B e MIH).

A partir de 1975, o hormônio hipotalâmico liberador de gonadotrofinas $(\mathrm{GnRH})$ foi introduzido como um tratamento alternativo, com a vantagem do uso intranasal e de não provocar o hiperestímulo androgênico. Pode provocar certo grau de rinite. O tratamento é realizado com o $\mathrm{GnRH}$ nativo, na dose de $200 \mu \mathrm{g}, 6$ vezes ao dia, durante 6 semanas. Esta apresentação nasal não é disponível em nosso meio, e o elevado custo do tratamento e a necessidade de doses múltiplas diárias reduzem a aderência. Alternativamente, pode-se empregar um dos tipos de GnRH agonista hiperativo, como por exemplo o Buserelin ${ }^{\circledR}$, que por sua maior potência e efeito mais prolongado pode ser utilizado em dias alternados, na dose de $10 \mu \mathrm{g}$ por via intranasal, durante 6 a 8 semanas. O GnRH agonista hiperativo de depósito não deve ser utilizado no tratamento do criptorquismo pois causa uma ação inibidora prolongada do eixo hipotalâmico-hipofisário-testicular (down regulation dos receptores de $\mathrm{LH}$ ).

As principais contra-indicações do tratamento hormonal são a hérnia inguinal, cisto de cordão, hidrocele e varicocele, devido ao risco de compressão do funículo espermático e isquemia testicular.

Os efeitos sistêmicos do tratamento hormonal são discretos e de curta duração. Raramente ocorrem

Tabela 3. Gonadotrofinas coriônicas e recombinantes hipofisárias disponíveis no mercado Brasileiro.

\begin{tabular}{ccc}
\hline Nome comercial & Hormônio & Empresa \\
\hline $\begin{array}{c}\text { Gonal-f (75UI) } \\
\text { Luveris (75UI) }\end{array}$ & $\begin{array}{c}\text { FSH recombinante } \\
\text { LH recombinante }\end{array}$ & Serono \\
Ovidrel (6500UI) & hCG recombinante & \\
& & \\
Puregon (75UI) & FSH recombinante & Organon \\
Pregnyl (5000UI) & hCG urinário & \\
Menogon (75UI) & LH+FSH urinário & \\
Menopur (75UI) & LH+FSH urinário & Ferring \\
Choragon (1500 Ou 5000UI) & hCG urinário & \\
& & \\
Merional (75UI) & LH+FSH urinário & Meizler \\
Fostimon (75UI) & FSH urinário & \\
Choriomon (5000UI) & hCG urinário & \\
\hline
\end{tabular}


manifestações alérgicas cutâneas urticariformes, suficientemente importantes para exigir a suspensão do tratamento. As alterações genitais secundárias ao estímulo androgênico são a hiperemia e o leve escurecimento da pele da região genital, discreta rugosidade escrotal, aparecimento de pelos finos e curtos em região escrotal ou pubiana, ereção peniana de curta duração e aumento do comprimento peniano. A única manifestação presente 6 meses após o final do tratamento é o aumento peniano (média de $0,5 \mathrm{~cm}$; varição: $0-2,0 \mathrm{~cm}$ ). Alguns pacientes referem dor na região inguinal associada ao ingurgitamento do funículo espermático, sem evidência clínica de estrutura herniária.

Resposta parcial ao tratamento hormonal pode ser observada e tais pacientes podem receber um segundo ciclo hormonal após 4 a 6 meses. O segundo ciclo hormonal induz uma resposta satisfatória em $60 \%$ dos testículos inicialmente retráteis, enquanto raramente os testículos inicialmente retidos apresentam resposta adequada.

Em nosso Serviço, a resposta ao tratamento hormonal mostrou-se dependente da idade cronológica e do tipo e lateralidade do criptorquismo. Consideramos resposta adequada ao tratamento hormonal a localização intra-escrotal do testículo quando $\mathrm{em}$ repouso. Observamos que em meninos menores de 2 anos de idade apenas $2 \%$ dos testículos retidos apresentaram resposta clínica adequada, enquanto na mesma faixa etária $20 \%$ dos testículos retráteis responderam satisfatoriamente. Entre 2 e 4 anos, a resposta satisfatória foi observada em $20 \%$ dos testículos retidos e em $45 \%$ dos retráteis. Em crianças maiores de 4 anos, a localização intra-escrotal foi obtida em $25 \%$ dos testículos retidos e em $70 \%$ dos testículos retráteis.

Em relação à lateralidade do criptorquismo, a resposta clínica satisfatória ocorreu em $15 \%$ dos testículos retidos unilaterais e em $25 \%$ dos retidos bilaterais. Resposta adequada ao hCG pode ser obtida em $45 \%$ dos testículos retráteis unilaterais e em $60 \%$ dos retráteis bilaterais.

Antes do tratamento hormonal e $48 \mathrm{~h}$ após a $6^{\mathrm{a}}$ dose de hCG, a determinação da concentração de testosterona e inibina pode ser útil no reconhecimento da função das células de Leydig e Sertoli, respectivamente. Neste estímulo crônico, em semelhança ao observado no teste agudo, a dosagem de $\beta$-hCG permite confirmar o uso adequado da gonadotrofina durante o tratamento. Nas doses preconizadas durante o tratamento crônico com hCG, a resposta da testosterona é em média de $250 \mathrm{ng} / \mathrm{dl}$, sendo o mínimo aceito como normal de $150 \mathrm{ng} / \mathrm{dl}$.

\section{Criptorquismo e Fertilidade}

A esterilidade tem sido observada em 30 a $50 \%$ dos pacientes com criptorquismo unilateral e em $75 \%$ dos casos de criptorquismo bilateral. Existe grande variabilidade de informações e dados conflitantes, em geral decorrentes das múltiplas classificações, diferentes protocolos de tratamento, idades diferentes do tratamento hormonal ou cirúrgico, desconsideração quanto à localização inicial dos testículos ou presença de malformações do epidídimo e deferente. O posicionamento precoce dos testículos na região intraescrotal pode potencialmente impedir ou retardar a evolução da lesão testicular, reduzindo o comprometimento testicular contralateral nos casos de criptorquismo unilateral.

Os dois critérios mais freqüentemente empregados na determinação da fertilidade são o espermograma e a taxa de paternidade. Em estudo recente, a comparação de mais de 300 homens criptorquídicos com um número semelhante de controles da população geral, observou que a taxa de paternidade de indivíduos com criptorquismo unilateral foi semelhante aos controles $(75 \%)$, mas esteve reduzida em pacientes com criptorquismo bilateral (53\%). Estes achados apontam para um comprometimento menos grave da fertilidade em relação ao previamente descrito. A maior parte dos estudos não relaciona a taxa de fertilidade à idade do tratamento, porém ainda é preciso que se avalie um número maior de casos tratados no final do primeiro ano de vida para que se possa definir a influência da idade do tratamento sobre a fertilidade.

\section{Criptorquismo e Neoplasia Testicular}

O risco de neoplasia testicular em pacientes criptorquídicos é de 48,9 por 100.000, o que representa um risco 22 vezes maior que o da população geral. $\mathrm{O}$ risco de tumor em um testículo intra-abdominal é 6 vezes maior que o de outras localizações. A orquiopexia não parece ser um fator protetor importante no desenvolvimento tumoral, embora para alguns autores a idade da orquiopexia possa exercer um certo papel protetor. De qualquer forma, o tratamento do criptorquismo permite um exame clínico mais fácil da gônada e maior eficiência na observação ao longo prazo.

\section{Seguimento Clínico Longitudinal}

A vacinação contra a caxumba é obrigatória, pois pode prevenir a orquite, que mais provavelmente se instala no testículo com melhor vascularização e função.

Após correção do criptorquismo, o paciente deve ser reexaminado anualmente até a puberdade, quando então a função testicular será novamente 


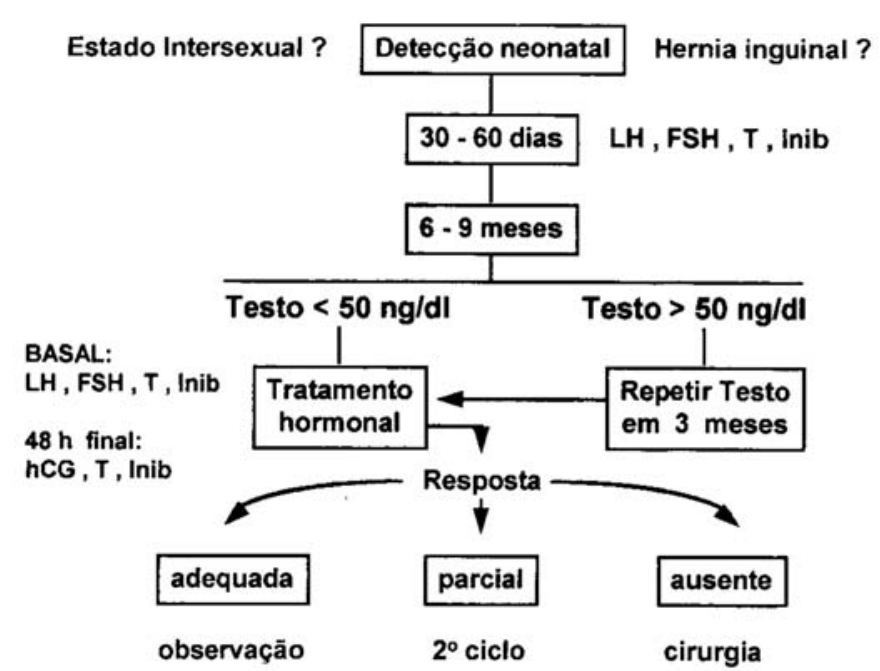

Figura 2. Conduta frente ao criptorquismo neonatal.

investigada, com determinação das concentrações de LH, FSH, testosterona e se possível inibina. Ao final da puberdade, especialmente após um ano de atingido o estágio genital V de Tanner, a contagem de espermatozóides e a avaliação qualitativa do sêmen trarão importantes informações sobre a fertilidade. A avaliação rotineira do volume e consistência testicular, bem como a presença de nódulo ou aumento assimétrico da gônada, deve ser cuidadosamente observada. O uso concomitante do exame ultrassonográfico permitirá a detecção precoce dos tumores testiculares.

\section{Conduta Terapêutica Frente ao}

\section{Reconhecimento Neonatal do Criptorquis-} mo

A figura 2 resume as principais etapas da conduta quando do diagnóstico neonatal do criptorquismo.

\section{REFERÊNCIAS}

1. Kogan S. Cryptorchidism. Clin Pediatr Urol 1990;2:1050-83.

2. Rajfer J. Congenital anomalies of the testis. In: Walsh PC, Vaughan ED, Retik AB, Wein A, editors. Campbell's Urology. Philadelphia:WB Saunders; 1992.p. 1543-61.

3. Gill B, Kogan S. Cryptorchidism - current concepts. Pediatr Clin North Am - Pediatr Urol 1997;44:121 1-27.

4. Chilvers C, Dudley NE, Gough MH, Jackson MB, Pike MC. Undescended testis: the effect of treatment on subsequent risk of subfertility and malignancy. J Pediatr Surg 1986;21:691-6.

5. Longui CA, Calliari LE, Rodrigues AG, Kochi C, Domingues AM, Kaneko W, et al. Criptorquismo: conceitos básicos e tratamento hormonal. J Pediatr (Rio)
1994;70:331-7.

6. Longui CA. Criptorquismo. In: Longui CA, Monte O, Calliari LEP, editores. Endocrinologia para o Pediatra. São Paulo:Atheneu Editora; 1998.p.209-12.

7. Longui CA. Morfologia e função testicular em crianças com criptorquismo menores de 4 anos de idade: importância da determinação sérica de inibina após estímulo gonadotrófico. Tese de doutoramento, FMUSP; 1993.

8. Longui CA, Arnhold IJ, Mendonça BB, D'Osvaldo AF, Bloise W. Serum inhibin levels before and after gonadotropin stimulation in cryptorchid boys under age 4 years. J Pediatr Endocrinol Metab 1998;1 1:68792.

Endereço para correspondência:

Carlos Alberto Longui

Departmento de Pediatria

Faculdade de Ciências Médicas -

Santa Casa de São Paulo

Rua Cesário Motta Júnior 112

01221-900 São Paulo, SP

E-mail: fisiolab@santacasasp.org.br 